Article

\title{
Antibacterial Efficacy and Mechanism of Mannosylerythritol Lipids-A on Listeria monocytogenes
}

\author{
Xiayu Liu ${ }^{1}$, Qin Shu ${ }^{1}$, Qihe Chen ${ }^{1}{ }^{\mathbb{D}}$, Xinxin Pang ${ }^{1}$, Yansha $\mathrm{Wu}^{1}{ }^{1}$, Wanyi Zhou ${ }^{1}$, Yajing Wu ${ }^{1}$, \\ Jianrui Niu $^{2, *}$ and Xinglin Zhang ${ }^{1,2, * \mathbb{D}}$ \\ 1 Department of Food Science and Nutrition, Zhejiang University, Yuhangtang Rd.866, Hangzhou 310058, \\ China; Xiayuliu@zju.edu.cn (X.L.); 21713041@zju.edu.cn (Q.S.); chenqh@zju.edu.cn (Q.C.); \\ 21713072@zju.edu.cn (X.P.); yanshawu@zju.edu.cn (Y.W.); munaiyi0612@zju.edu.cn (W.Z.); \\ 21913063@zju.edu.cn (Y.W.) \\ 2 College of Agriculture and Forestry, Linyi University, Linyi 276005, China \\ * $\quad$ Correspondence: niujianrui@lyu.edu.cn (J.N.); xinglinzhang@zju.edu.cn (X.Z.); Tel.: +86-571-86984316 (X.Z.)
}

Received: 15 September 2020; Accepted: 20 October 2020; Published: 21 October 2020

\begin{abstract}
Mannosylerythritol lipids-A (MEL-A) is a novel biosurfactant with excellent surface activity and potential biomedical applications. In this study, we explored the antibacterial activity and the underlying mechanisms of MEL-A against the important food-borne pathogen Listeria monocytogenes. The bacterial growth and survival assays revealed a remarkable antibacterial activity of MEL-A. Since MEL-A is a biosurfactant, we examined the cell membrane integrity and morphological changes of MEL-A-treated bacteria by biochemical assays and flow cytometry analysis and electron microscopes. The results showed obvious damaging effects of MEL-A on the cell membrane and morphology. To further explore the antibacterial mechanism of MEL-A, a transcriptome analysis was performed, which identified 528 differentially expressed genes (DEGs). Gene ontology (GO) analysis revealed that the gene categories of membrane, localization and transport were enriched among the DEGs, and the analysis of the Kyoto Encyclopedia of Genes and Genomes (KEGG) pathways demonstrated significant changes in the maltodextrin $\mathrm{ABC}$ transporter system and stress response system. Furthermore, the growth of $L$. monocytogenes could also be significantly inhibited by MEL-A in milk, a model of a real food system, suggesting that MEL-A could be potentially applied as an natural antimicrobial agent to control food-borne pathogens in the food industry.
\end{abstract}

Keywords: Mannosylerythritol lipids-A (MEL-A); Listeria monocytogenes; antibacterial activity; RNA-Seq; milk; food-borne pathogen

\section{Introduction}

Food safety is one of the most important public health issues in the world. With the continuous development of globalization, the factors affecting food safety are becoming more and more diverse and complicated, and the incidence of food-borne diseases is constantly increasing. An analysis by the World Health Organization (WHO) finds that approximate 600 million people are infected with food-borne diseases each year, which causes more than 420,000 deaths [1]. Moreover, it is estimated that the real incidence of food-borne diseases is much higher than the reported incidence [2]. Among the numerous pathogenic factors, food-borne pathogens are major causes of food-borne diseases.

L. monocytogenes is a short rod-shaped Gram-positive bacterial and one of the most popular food-borne pathogens all over the world. In 1926, it was described for the first time in an outbreak which interfered with guinea pigs and rabbits [3] and recognized as a food-borne pathogen in 1980s [4]. In recent years, the number of people infected with listeriosis has constantly been rising and the 
mortality rate is extremely high (up to $20 \%-30 \%$ ) [5]. Compared with healthy people, the mortality of susceptible people (elderly, children, pregnant women and immunocompromised individuals) is even higher. From the epidemiological data, there are three major types of $L$. monocytogenes $(1 / 2 a, 1 / 2 b$, and $4 \mathrm{~b}$ ) that are associated with human infections [6]. L. monocytogenes can survive in many extreme environments (low temperature, low $\mathrm{pH}$, high salt concentration, etc.), so it is widely distributed in nature and easily causes food contamination in dairy products, seafood, meat, vegetables and ready-to-eat food [7]. Hence, L. monocytogenes is a continuous threat to the food industry due to its high lethality, and its intrinsic and acquired tolerance to commonly used antimicrobial agents. Therefore, there is great demand for novel reagents (especially natural food preservatives) that can prevent L. monocytogenes contamination in food industry.

Biosurfactants are an important class of surfactants, which can be produced by microorganisms using sugar, oil, etc. as substrates. According to different structures, biosurfactants can be divided into glycolipids, lipopeptides and lipoproteins, phospholipids, fatty acids and polymeric biosurfactants [8,9]. Glycolipids (including rhamnolipids, sophorolipids, trehalolipids, etc.) are considered as among the most important types of biological surfactants because of their excellent antibacterial activity against common pathogens. Mannosylerythritol lipids (MELs) are a representative type of glycolipids, which not only exhibit great emulsification, surface activity and biodegradability, but also have the functions of inhibiting microbial growth, inducing cell differentiation, and improving gene transfection efficiency [10]. Based on the difference of the fatty acid chain and acetyl group, MELs can be divided into four different configurations: MEL-A, MEL-B, MEL-C, and MEL-D [11]. Four different MELs can be produced by different microorganisms through different metabolic pathways. In our previous research, MELs showed outstanding antibacterial effects against Staphylococcus aureus [12] and Bacillus cereus [13]. Among the four different MELs, MEL-A has a simpler production route and more efficient antibacterial properties. To date, however, there has been little discussion about the inhibitory effect of MEL-A on L. monocytogenes.

The goal of this work was to study the antibacterial activity and the mechanism of MEL-A against L. monocytogenes, through biochemical analyses, morphology observation, transcriptome profiling and other methods. Furthermore, milk was used as a model system to investigate the antibacterial effect of MEL-A in complex food systems, so as to explore the potential application of MEL-A in the food industry. In this study, we found that MEL-A has an excellent inhibitory effect on L. monocytogenes by causing damages on the cell membrane. Through transcriptome analysis, we discovered that MEL-A could lead to the dramatic reprograming of gene expression, particularly for the $A B C$ transporter systems and other important pathways mainly involved in stress response.

\section{Materials and Methods}

\subsection{Microorganisms and Chemicals}

The bacterial L. monocytogenes wild-type strain EGD-e (ATCC BAA-679) was obtained from American Tissue Culture Collection and maintained in slants of brain-heart infusion (BHI) agar or broth at $4{ }^{\circ} \mathrm{C}$. Other strains were stored in our laboratory. Pasteurization-processed skimmed milk and whole milk were purchased from a local grocery store (Wal-mart Superstore, Hangzhou, China). All the chemicals used in this study were of analytical grade.

\subsection{Production and Purification of MEL-A}

MEL-A was produced and purified as previously reported by Fan et al. [14]. After 7 days of fermentation, MELs were produced from vegetable oil by Pseudozyma aphidis DSM 70,725 and then mixed with the same volume of ethyl acetate. The organic layer was separated by extraction, and the ethyl acetate was evaporated under reduced pressure. Then, the crude MELS were washed twice with methanol and cyclohexane to remove the residual oil and fatty acids, which were also purified through a silica gel column and then analyzed by thin layer chromatography (TLC) (Silica gel 
60F, chloroform:methanol:water $=70: 15: 2, v / v)$, liquid chromatography-mass spectrometry (LC-MS) (Agilent, Sacramento, CA, USA), gas chromatography-mass spectrometry (GC-MS) (Hiden, London, UK) and nuclear magnetic resonance (NMR) (Thermo Fisher Scientific, Waltham, MA, USA) [15]. Experimental results showed that the MEL-A accounts for more than $80 \%$ of the MELS.

\subsection{Production and Purification of $M E L-A$}

\subsubsection{Determination of Minimum Inhibition Concentration (MIC) in BHI}

MIC is one of the most common indicators for detecting the lowest concentration of antimicrobial agent that prevents the visible cell growth of microorganisms under specific conditions [16]. MEL-A were added to BHI broth by two-fold serial dilution method, the final concentrations were $0,4,8,16$, 32,64 , and $128 \mu \mathrm{g} / \mathrm{mL}$, respectively. Fifty milliliters of L. monocytogenes was cultured at $37^{\circ} \mathrm{C}$ in $\mathrm{BHI}$ until the exponential phase, and then washed three times with phosphate buffer saline (PBS) and diluted to obtain a final concentration of $1.0 \times 10^{6} \mathrm{CFU} / \mathrm{mL}$ as the seed. Then, $1 \mathrm{~mL}$ of $L$. monocytogenes was inoculated into a $50 \mathrm{~mL}$ reagent bottle containing sterile $\mathrm{BHI}$ with different concentrations of MEL-A, and all the flasks were incubated in an orbital shaker $\left(37^{\circ} \mathrm{C}, 180 \mathrm{rpm}\right.$ ) (Thermo Fisher Scientific, Waltham, MA, USA). After remaining overnight, the bacterial concentration was taken out and monitored by measuring the $\mathrm{OD}_{600 \mathrm{~nm}}$ value using a microplate reader (Thermo US).

\subsubsection{Bacterial Growth Curve in BHI}

To assess the inhibitory effect of different MEL-A concentrations on different growth stages of L. monocytogenes, the bacterial growth curve was drawn. After preparing the BHI broth with different concentrations of MEL-A $(0,16,32,64,128 \mu \mathrm{g} / \mathrm{mL})$, the logarithmic phase of L. monocytogenes was inoculated into shake flasks and cultured at $37^{\circ} \mathrm{C}$. Then, $100 \mu \mathrm{L}$ of bacterial suspension was taken out from the flask every $2 \mathrm{~h}$, diluted and spread evenly on the BHI plate, and incubated in a $37^{\circ} \mathrm{C}$ incubator. The growth curve of L. monocytogenes was drawn using the plate counting method and expressed as a $\log \mathrm{CFU} / \mathrm{mL}$ sample [17].

\subsubsection{Bacterial Survival Rate}

Cell Counting Kit-8 (Beyotime Biotechnology, Shanghai, China) was a rapid and highly sensitive detection kit based on WST-8 (2-(2-methoxy-4-nitrophenyl)-3-(4-nitrophenyl)-5-(2,4-disulfophenyl)$2 \mathrm{H}$-tetrazolium, monosodium salt) and widely used in cell proliferation and cytotoxicity detection [18]. It was used to further determine the survival rate of L. monocytogenes treated with MEL-A. The BHI broth was prepared with different concentrations of MEL-A $(0.5 \times \mathrm{MIC}, 1 \times \mathrm{MIC}, 2 \times \mathrm{MIC})$, and then $1 \mathrm{~mL}$ of L. monocytogenes $\left(1.0 \times 10^{6} \mathrm{CFU} / \mathrm{mL}\right)$ in the logarithmic growth phase was inoculated into each reagent bottle and cultured at $37^{\circ} \mathrm{C}$ for $12 \mathrm{~h}$. Then, the bacterial cultures were diluted 100 times. According to the kit instructions, $180 \mu \mathrm{L}$ of diluent and $20 \mu \mathrm{L} \mathrm{CCK}-8$ solution were added to a 96-well plate and mix gently. After incubating in a cell incubator at $37^{\circ} \mathrm{C}$ for $0.5,1$ and $2 \mathrm{~h}$, the values of $\mathrm{OD}_{450}$ and $\mathrm{OD}_{650}$ were measured with a microplate reader (Thermo Fisher Scientific, Waltham, MA, USA). The survival rate of L. monocytogenes was calculated by the following formula (1):

$$
\mathrm{S}=100 \% \times\left(\mathrm{M}\left(\mathrm{OD}_{450}\right)-\mathrm{M}\left(\mathrm{OD}_{650}\right)\right) /\left(\mathrm{C}\left(\mathrm{OD}_{450}\right)-\mathrm{C}\left(\mathrm{OD}_{650}\right)\right)
$$

S: survival rate; M: MEL-A treated; C: control.

\subsection{Antibacterial Mechanism of MEL-A}

\subsubsection{The Integrity of Cell Membrane Assays}

To determine the integrity of cell membrane, the leakage of intracellular constituents including nucleic acids and proteins was measured as described by the literature [19]. As in the method described 
above, the L. monocytogenes was inoculated into different concentrations of MEL-A $(0.5 \times$ MIC and $1 \times \mathrm{MIC}$ ) and cultured at $37^{\circ} \mathrm{C}$ and $180 \mathrm{rpm}$. After $12 \mathrm{~h}$, the bacterial suspension was taken out and centrifuged at $8000 \mathrm{rpm}$ for $3 \mathrm{~min}$, and then the supernatants were filtered by a $0.22 \mu \mathrm{m}$ membrane. To determine the concentrations of the leakage of intracellular constituents that consist of nucleic acids and proteins, the absorbance of the supernatants was measured at $260 \mathrm{~nm}$ and $280 \mathrm{~nm}$ by a UV-visible spectrophotometer (Agilent, Sacramento, CA, USA).

\subsubsection{Flow Cytometric Analysis}

Propidium iodide (PI) is a nucleic acid dye which cannot penetrate the complete cell membrane of normal cells or early apoptotic cells but can stain the nucleus red through the cell membrane of late apoptotic and necrotic cells [20]. Thus, it was used to distinguish the survival early cells from necrotic or late apoptotic cells. The suspensions of L. monocytogenes in BHI broth (treated with MEL-A at the concentration of $0,0.5 \times \mathrm{MIC}, 1 \times \mathrm{MIC}$, and $2 \times \mathrm{MIC}$ ) were incubated at $37^{\circ} \mathrm{C}, 180 \mathrm{rpm}$ for $12 \mathrm{~h}$ as above. Then, the cells were washed twice with cold PBS and gently mixed $1-5 \times 10^{5}$ cells with $10 \mu \mathrm{L}$ PI staining solution. After that, the mixture was incubated at room temperature in the dark for 10-15 min. The samples were monitored by flow cytometric (FACSVerse, Newark, NJ, USA) and the data were analyzed by FlowJo 10.

\subsubsection{Morphological Observation of L. monocytogenes}

L. monocytogenes was cultured in BHI (treated with MEL-A at the MIC) at $37^{\circ} \mathrm{C}$ for $12 \mathrm{~h}$, while the bacterial cells without MEL-A were used as the control. The samples were washed with PBS and $2.5 \%$ glutaraldehyde at $4{ }^{\circ} \mathrm{C}$ overnight. Then, the bacterial was observed by SEM (Hitachi SU-8010, Tokyo, Japan) and TEM (Hitachi H-7650, Tokyo, Japan) in the bio-ultrastructure analysis Lab of Analysis center of Agrobiology and environmental science (Zhejiang University).

\subsubsection{RNA Sequencing}

Approximately $1 \times 10^{6} \mathrm{CFU}$ of L. monocytogenes were inoculated into $50 \mathrm{~mL}$ of BHI broth (treated with MEL-A at the MIC) and the bacterial cells without MEL-A was used as the control, and grown at $37^{\circ} \mathrm{C}$ until the exponential phase. The bacterial solutions were centrifuged at room temperature (5 min; $4000 \mathrm{rpm}$ ) and were quickly frozen in liquid $\mathrm{N}_{2}$ as described previously [21]. Strand-specific libraries were generated using NEBNext ${ }^{\circledR}$ UltraTM RNA Library Prep Kit (New England Biolabs, Los Angeles, CA, USA), then the library preparations were sequenced on an Illumina Novaseq platform and $150 \mathrm{bp}$ paired-end reads were generated. Then, the quantification of the gene expression level was analyzed by HTSeq v0.6.1 (New South Wales, Sydney) and the differential expression analysis of two conditions was performed using the DESeq R package (1.18.0) (New South Wales, Sydney). Gene ontology (GO) enrichment analysis of differentially expressed genes was implemented by the GOseq $\mathrm{R}$ package, and the KOBAS software (Beijing, China) was used to test the statistical enrichment of the differential expression genes in the Kyoto Encyclopedia of Genes and Genomes (KEGG) pathways.

\subsubsection{Real-Time PCR Analysis}

Total RNA was isolated as described above and cDNA was synthesized with the PrimeScript RT reagent Kit (Thermo Fisher Scientific, Waltham, MA, USA) with the gDNA Eraser. Real-time PCR on this cDNA was performed using the TB Green ${ }^{\circledR}$ Premix Ex Taq ${ }^{\mathrm{TM}}$ (Tli RNaseH Plus) Kit (Thermo Fisher Scientific, Waltham, MA, USA) and an Applied Biosystems ${ }^{\mathrm{TM}}$ QuantStudio $^{\mathrm{TM}} 3$ instrument (Thermo Fisher Scientific, Waltham, Massachusetts, USA). The expression of drm was used as a housekeeping control. The QuantStudioTM Design \& Analysis Software 1.3.1 (Thermo Fisher Scientific, Waltham, MA, USA) was used to calculate the Ct values and the relative gene expression was calculated using the $2^{-\Delta \Delta C t}$ method [22]. 


\subsection{Inhibition of Bacterial Growth in Milk by MEL-A}

The bacterial growth curve was drawn to determine the antibacterial effect of MEL-A against L. monocytogenes in whole milk and skimmed milk. Approximately $1 \times 10^{6} \mathrm{CFU}$ of L. monocytogenes were inoculated into $25 \mathrm{~mL}$ of milk with different concentrations of MEL-A $(0 \mu \mathrm{g} / \mathrm{mL}, 512 \mu \mathrm{g} / \mathrm{mL}$, $1024 \mu \mathrm{g} / \mathrm{mL}$ ) and incubated statically at $37^{\circ} \mathrm{C}$. Then, the plate counting method described above was used to count the colonies of each sample every $12 \mathrm{~h}$.

\subsection{Statistical Analysis}

All experiments were performed with three biological replicates and the data were presented as the mean \pm standard deviation. All significant differences were carried out using a one-way analysis of variance (ANOVA) and Duncan's multiple range test (DMRT). And all the tests were considered statistically significant only when $p<0.05$.

\section{Results and Discussions}

\subsection{Inhibition Effect of MEL-A against L. monocytogenes}

\subsubsection{MIC of MEL-A against L. monocytogenes}

The minimum inhibitory concentration (MIC) was designed to determine the antimicrobial activity of MEL-A on L. monocytogenes. As we can see from Figure S1, there was a significant inhibitory effect of MEL-A when the concentration reached $32 \mu \mathrm{g} / \mathrm{mL}$, which was regarded as the MIC. This finding was in agreement with previous findings [23], showing the strong antibacterial activity of MEL-A. In addition, compared with the MIC of MELs against B. cereus [13], our results also indicated that the pure substance MEL-A had a better antibacterial effect than the mixture of MELs.

\subsubsection{Effect on Bacterial Growth}

In order to further confirm the antibacterial activity of MEL-A against L. monocytogenes, the Cell Counting Kit-8 was used to detect the number of living cells [18,24]. In the presence of electronic coupling reagents, WST-8 in the Cell Counting Kit-8 (CCK-8) can be reduced to orange formazan and the color intensity has a linear relationship with the number of cells. Therefore, we can judge the number of living cells in different MEL-A treatment groups by the absorbance value. The living cells continuously decreased with the increase in MEL-A concentration and the extension of culture time (Figure 1A). After two hours of incubation, only $63.65 \%(0.5 \times \mathrm{MIC}), 52.57 \%(1 \times \mathrm{MIC})$ and $44.30 \%$ $(2 \times \mathrm{MIC})$ of L. monocytogenes survived.
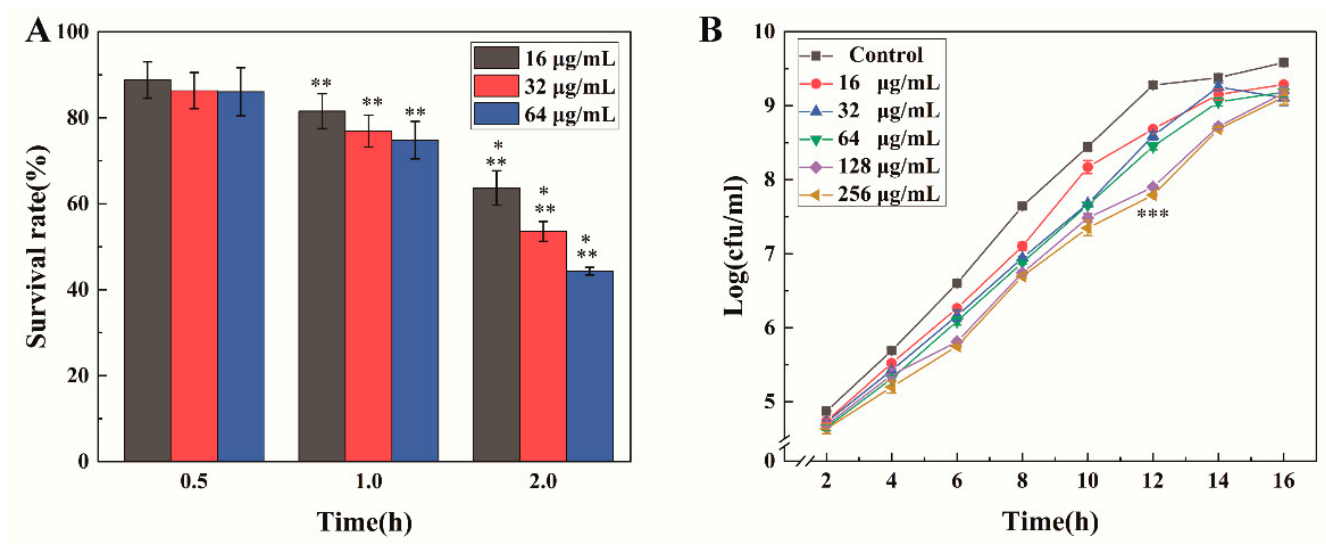

Figure 1. The effect of mannosylerythritol lipids-A (MEL-A) on bacterial growth. (A): survival rate of L. monocytogenes treated with MEL-A; (B): the effect of MEL-A on the L. monocytogenes growth curve.

* (one asterisk) indicates a significant difference in the comparison between different concentrations 
at the same time. ${ }^{* *}$ (two asterisks) indicate a significant difference in the comparison between the same concentration at different times. ${ }^{* * *}$ (three asterisks) indicates that the $128 \mu \mathrm{g} / \mathrm{mL}$ treatment group is significantly different from the control group.

Bacterial growth assay showed that the MEL-A had an inhibition effect on L. monocytogenes in the logarithmic growth phase (Figure 1B). The growth curve of L. monocytogenes treated with MIC $(32 \mu \mathrm{g} / \mathrm{mL})$ was approximately $1 \log$ lower than that of the control group from 8 to $12 \mathrm{~h}$. When the concentration of MEL-A reached $128 \mu \mathrm{g} / \mathrm{mL}$, the experimental group was approximately $1.5 \log$ lower than the control group at $12 \mathrm{~h}$. In summary, these results indicated the excellent inhibitory effect of MEL-A on L. monocytogenes.

\subsection{The Effect of MEL-A on the Integrity of Cell Membrane}

In order to confirm the possible impact of MEL-A on the cell membrane of L. monocytogenes, the leakage of nucleic acids and proteins which accounted for a large proportion of intracellular substance were measured [25]. As we can see from Figure 2, there was a significant difference in the absorbance at $260 \mathrm{~nm}$ (nucleic acids) and $280 \mathrm{~nm}$ (proteins) between the experimental groups and the control group. Therefore, the inhibitory effect of MEL-A on L. monocytogenes could be attributed to the damage to cell membrane. These findings were in agreement with several previous studies that investigated the inhibitory mechanism of antibacterial substances against L. monocytogenes [26-28].

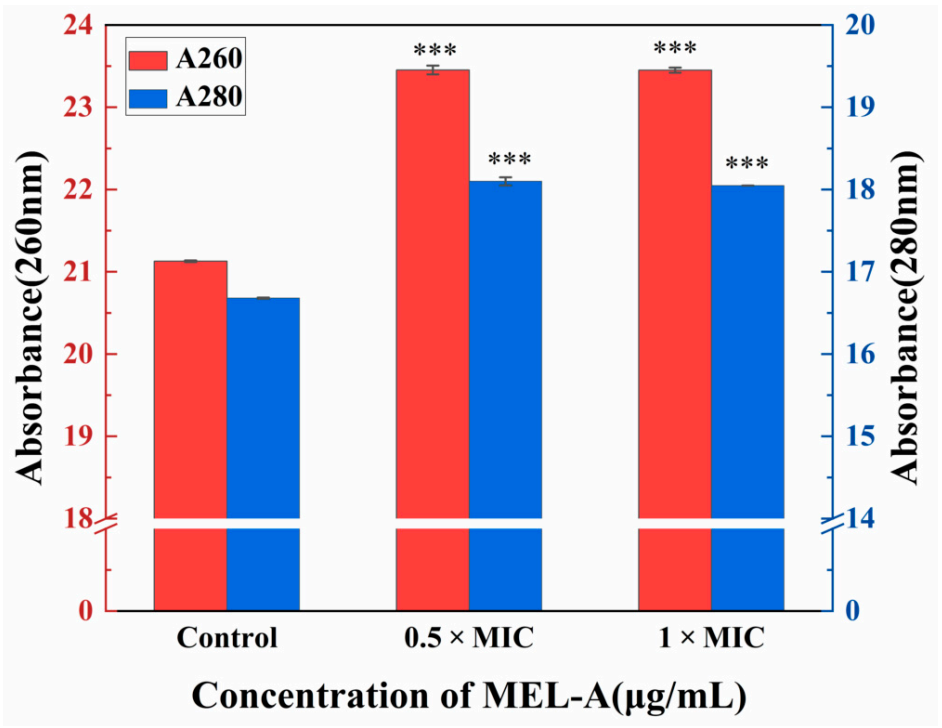

Figure 2. Leakage of the intracellular nucleic acids and proteins. ${ }^{* * *}$ (three asterisks) represents significant differences $(p<0.001)$ compared to controls. All experiments were performed with three biological replicates $(n=3)$.

\subsection{Flow Cytometric Analysis}

As one of the most advanced cell quantitative analysis techniques, Flow cytometry (FCM) has become widely used due to its fast speed, high precision and accuracy. PI (nucleic acid dye) cannot permeate the normal cells with complete cell membrane but can dye the nucleus red in the late apoptotic cells and necrotic cells with incomplete membrane. Hence, to detect the cell viability and the integrity of cell membrane more precise, the fluorescent staining with PI was employed [29]. Figure 3 shows that the fluorescence signal stained by PI in the MELA-treated group was much higher than the control. The difference between different concentrations $(0.5 \times \mathrm{MIC}, 1 \times \mathrm{MIC}, 2 \times \mathrm{MIC})$ was also apparent. From the table below we can see that the proportion of late apoptosis cells and necrotic cell is $1.19 \%$, $5.59 \%$, and $9.53 \%$ after treating with MEL-A at level of $0.5 \times$ MIC, $1 \times$ MIC, and $2 \times$ MIC, respectively, which was significantly more than $0.65 \%$ in the control group. In summary, these findings suggest that 
the destruction of cell membrane by MEL-A may be the main cause of the decrease in cell viability, which is also consistent with the results above.

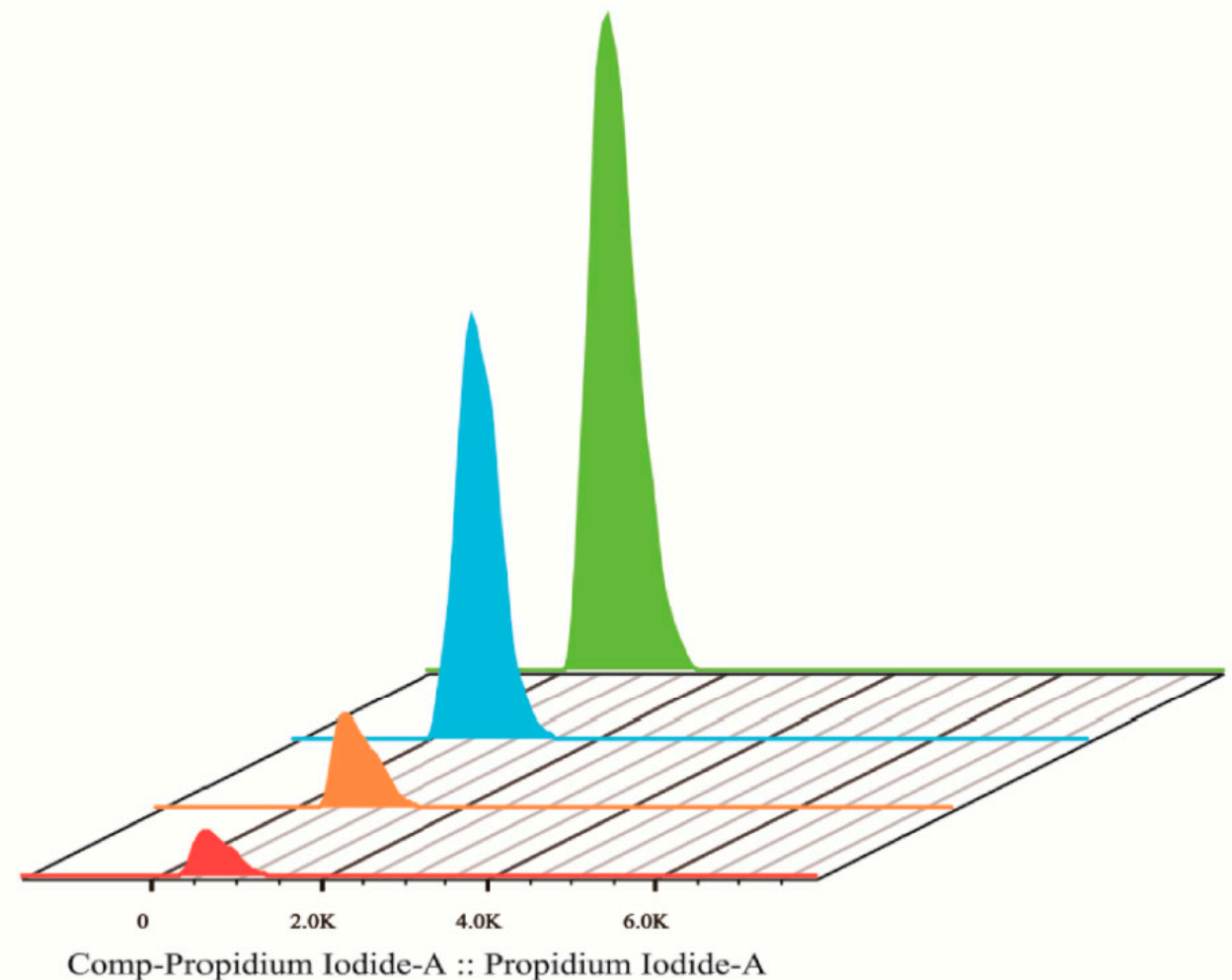

\begin{tabular}{|c|c|c|c|}
\hline & Sample & Number of cells stained & Percentage of PI stained \\
\hline$\square$ & Control & 518 & 0.65 \\
\hline$\square$ & $0.5 \times$ MIC & 1156 & 1.19 \\
\hline$\square$ & $1 \times$ MIC & 5420 & 5.59 \\
\hline$\square$ & $2 \times$ MIC & 9268 & 9.53 \\
\hline
\end{tabular}

Figure 3. Fluorescence plots of L. monocytogenes stained with propidium iodide (PI).

\subsection{Morphological Analysis of L. monocytogenes}

SEM was used to observe the external morphology changes of the L. monocytogenes cells [30]. The SEM images (Figure 4A) of the MEL-A-treated cells were significantly different to those of the untreated cells. The cells in the control group were short rod-shaped and plump, and the surface structure was smooth and flat. Conversely, the L. monocytogenes cells treated with MEL-A became slender and irregular (red arrows), and the surface roughness increased significantly. Even some holes were observed in the cytoplasmic membranes as shown by the blue arrows. These results visually show the destruction of MEL-A to the external structures of L. monocytogenes. 
Control

A
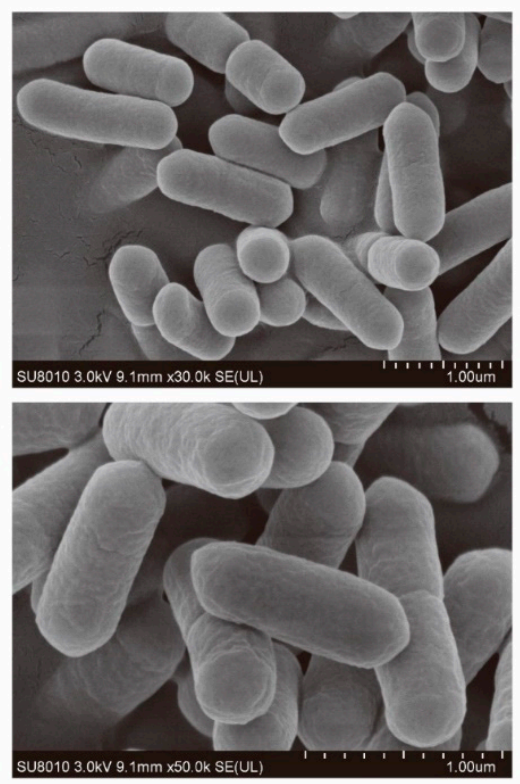

B
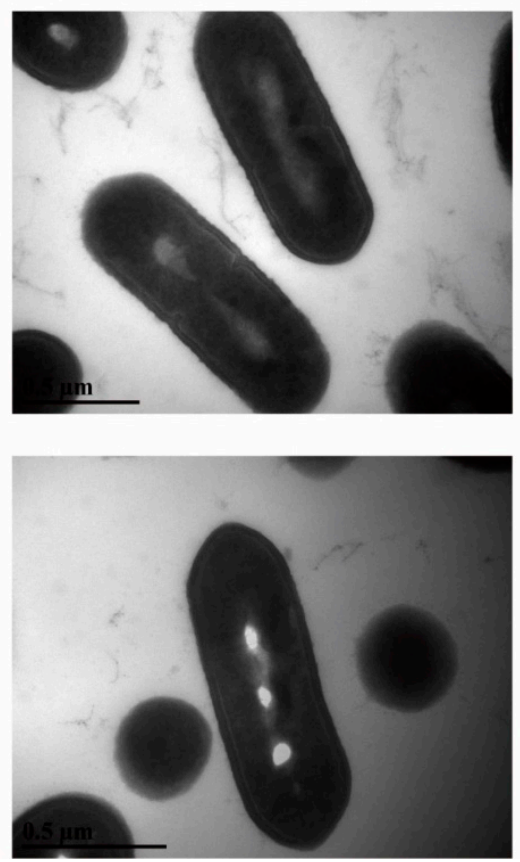

MEL-A
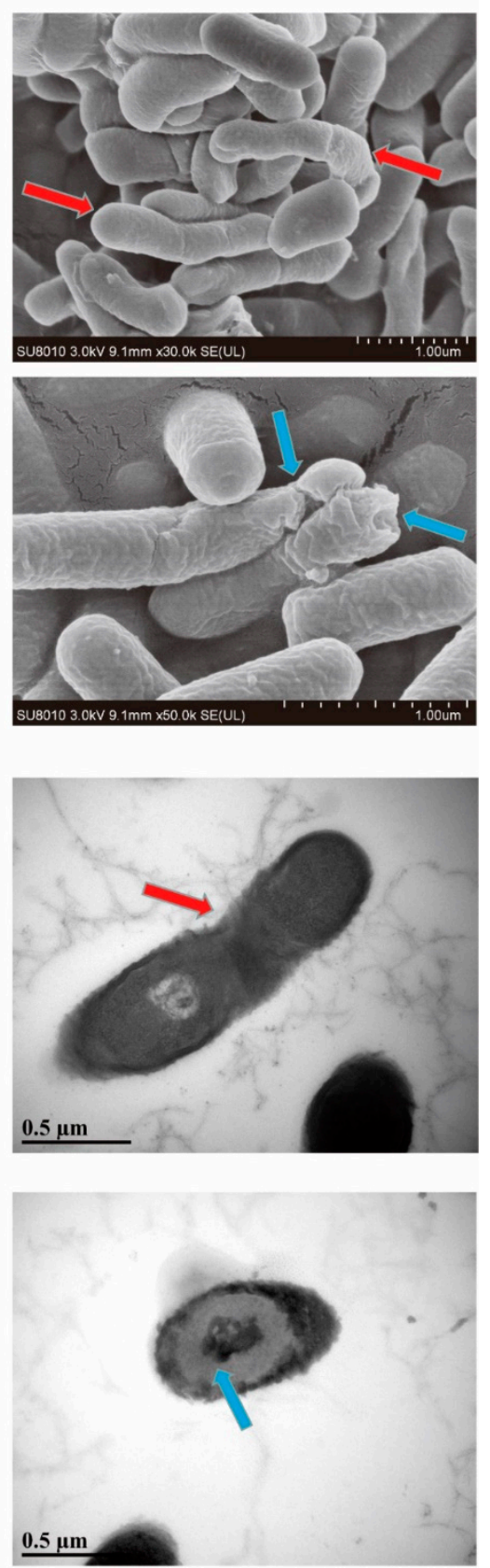

Figure 4. SEM (A) and TEM (B) micrographs of L. monocytogenes treated with MEL-A at the minimum inhibitory concentration (MIC) and control cells without treatment.

To further observe the external or internal cell structures changes caused by MEL-A, treated and untreated L. monocytogenes cells were examined by TEM. As the picture shows in Figure 4B, the cells in the control appeared normal with intact cell membranes and a dense cytoplasm. In contrast, L. monocytogenes with MEL-A treatment showed irregular shape with the sunken surfaces (red arrow), and the cross section was much shallower than the control (blue arrow). These results suggested that MEL-A had a stronger impact on the cell membrane and the leakage of intracellular contents including nucleic acids and proteins, which was similar to the effect of carvacrol on L. monocytogenes [30]. In conclusion, the morphological observation of L. monocytogenes provides compelling evidence that MEL-A is able to damage the cell membrane and eventually result in the leakage of intracellular substances and cell death. 


\subsection{Transcriptome Analysis}

\subsubsection{Analysis of the Differentially Expressed Genes (DEGs)}

Transcriptome analysis was applied to further elucidate the antibacterial mechanism of MEL-A. After MEL-A treatment, 528 differentially expressed genes were identified, including 311 upregulated and 217 downregulated genes (Figure 5). Within the upregulated genes, $28.3 \%$ of the genes with fold change $(\mathrm{FC})>5,5.5 \%$ of the genes with $\mathrm{FC}>20$, and there were three genes $(1 \mathrm{mo} 2180,1 \mathrm{mo} 0481,1 \mathrm{mo} 2336)$ with FC $>100$. Within the downregulated genes, $18 \%$ of the genes with $\mathrm{FC}>5,4.6 \%$ of the genes with FC $>20$, and there were two genes (lmo2125, lmo2124) with FC $>100$. Overall, these results suggested that there was a significant difference between the MEL-A treatment group and the control group.

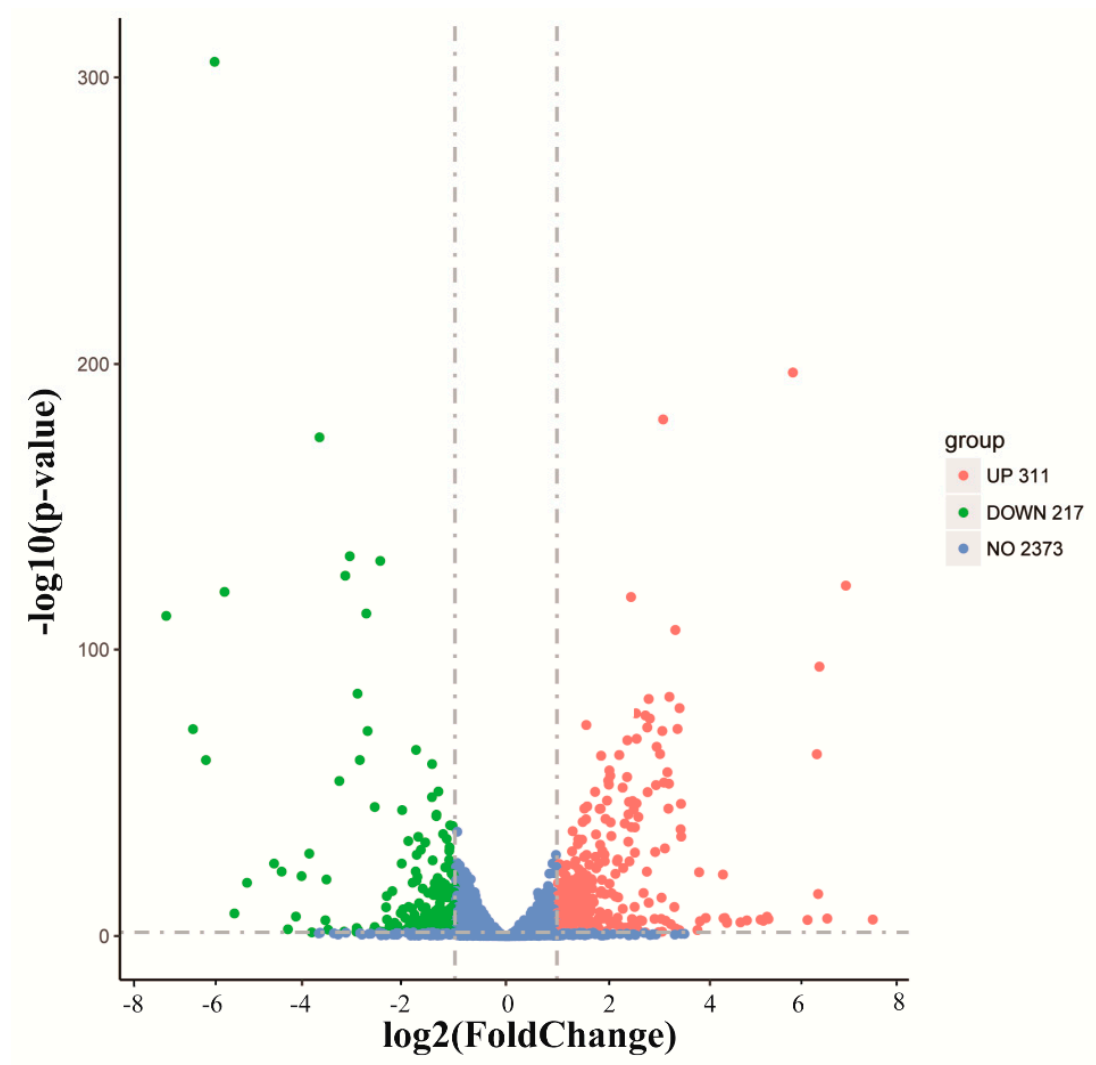

Figure 5. Analysis of deferentially expressed genes. The transcription data from the MEL-A-treated cells were compared to those from the control condition. The genes with a $p$-value $<0.05$ and $\mid \log 2$ (FoldChange) $\mid>1$ were considered differentially expressed genes (DEGs). Red dots indicate upregulated DEGs, green dots indicate downregulated DEGs and the blue dots indicate genes with no significant changes in expression.

\subsubsection{Gene Ontology (GO) Analysis}

The top thirty upregulated and downregulated genes by GO enrichment analysis are presented in Figure 6. The expression of genes involved in membrane localization and transport were significantly more regulated by the exposure to MEL-A (Table S1). After MEL-A treatment, the expression of the membrane-associated gene (membrane, membrane part and integral component of membrane) were upregulated (Figure 6A), which could be a protective response of bacteria to the stress caused by MEL-A [31]. The expression of genes involved in localization (lmo2124, lmo1740, etc.), transport (lmo2124, lmo2123, lmo2347, etc.) and the establishment of localization were downregulated (Figure 6B). These genes are mainly predicted to be related to the transport of sugar and amino acids, indicating that MEL-A directly affected the utilization of carbohydrates and the biosynthesis of amino acids, 
further affecting the ability of bacteria to repair themselves in extreme environments. This might be an important mechanism for MEL-A to inhibit bacterial growth.
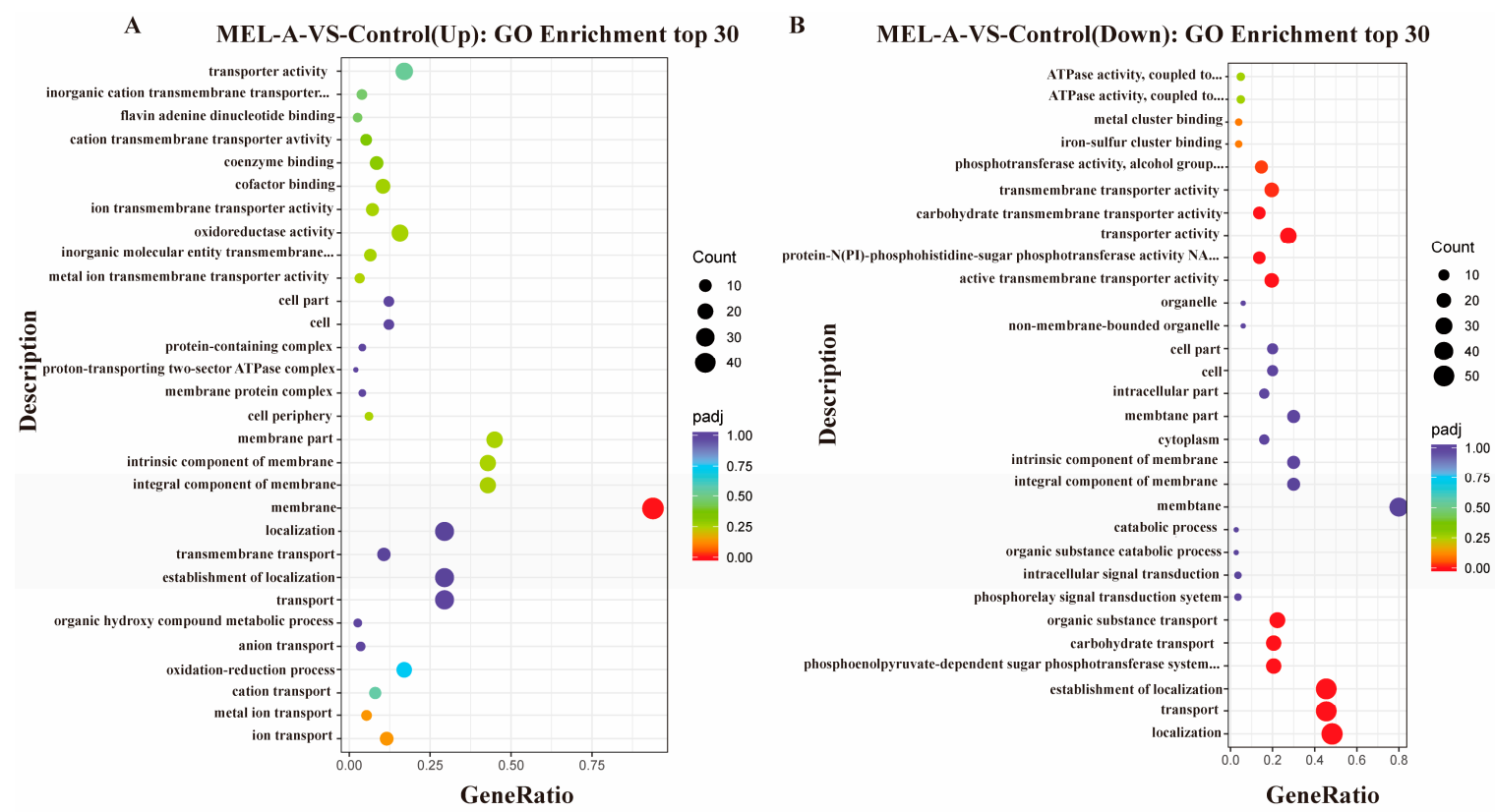

Figure 6. Scatter plot of gene ontology (GO) enrichment analysis: (A) scatter plot of the upregulated genes; and (B) scatter plot of the downregulated genes. The cut off value was screened based on $p<0.05$ and $|\log 2(\mathrm{FC})|>1$. The abscissa is the ratio of the number of differential genes annotated to GO Term to the total number of differential genes, and the ordinate is the GO Term.

\subsubsection{KEGG Analysis}

KEGG (Kyoto Encyclopedia of Genes and Genomes) is a comprehensive database that integrates the genome, chemistry and system function information. Altogether, five pathways (Table S2) were differentially regulated during cultivation in MEL-A, in which the $A B C$ transporters-associated genes (lmo2123, lmo2123, opuCD, etc.) were significantly regulated. ABC transporters belong to a large and diverse protein family that are mainly responsible for transporting various substrates (including ions and macromolecules) and are functionally important for the occurrence and functional maintenance of the membrane [32]. By MEL-A treatment, 14 genes related to $\mathrm{ABC}$ transporters were upregulated and 36 genes were downregulated. Among the most differentially expressed genes, we detected a significantly upregulated gene cluster (Figure 7B) with an important role in glycine/betaine transport and a downregulated gene cluster (Figure 7C) with an important role in sugar transport. 


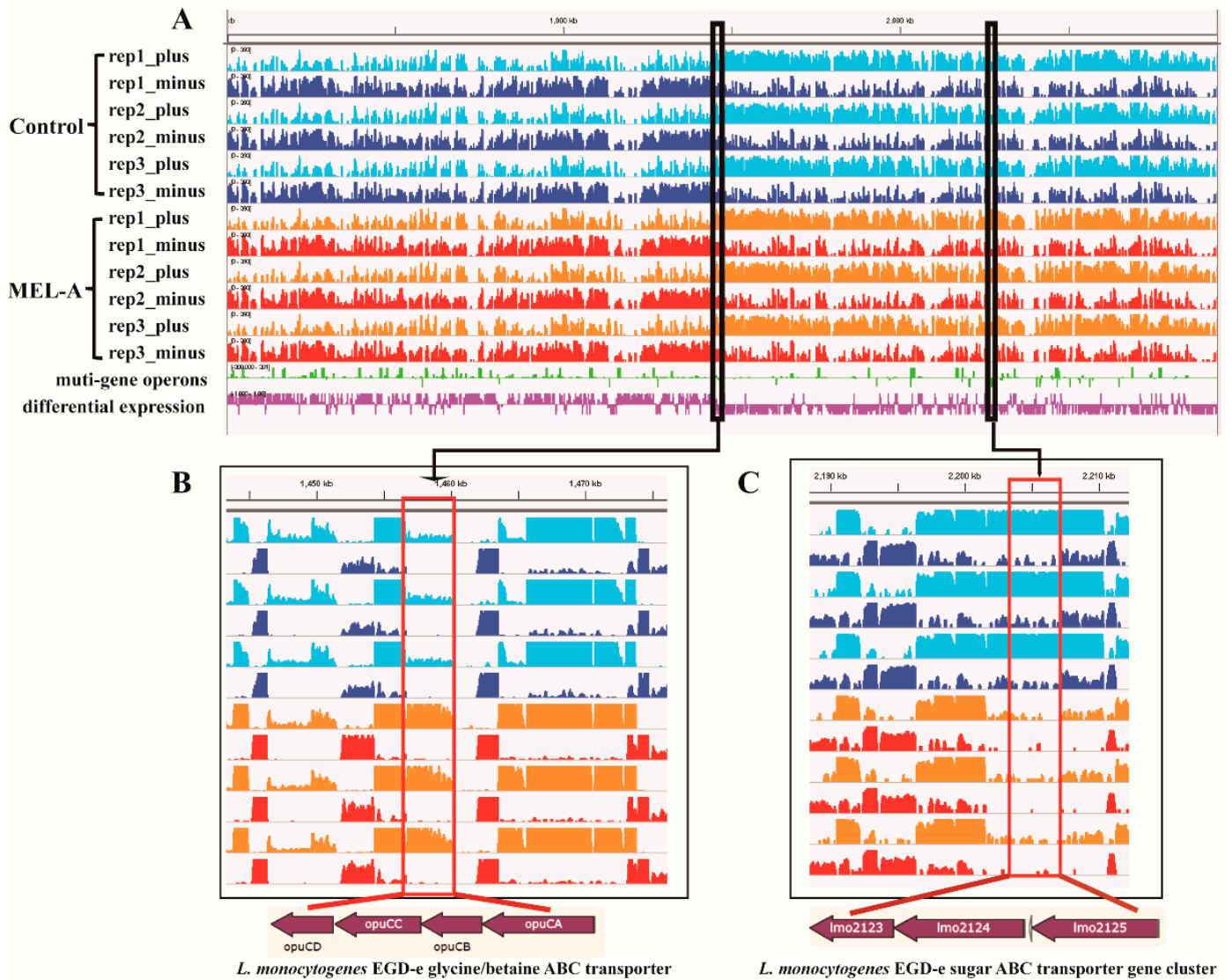

Figure 7. Transcriptome analysis of L. monocytogenes: (A) coverage plots of RNA-seq data aligning to chromosome DNA. The $y$ axis represents the reads coverage while the $x$ axis denotes the genomic location. Light blue (control) or orange (MEL-A) tracks are reads aligned to the plus strand and blue (control) or red (serum) tracks are reads aligned to the minus strand. Multi-gene operons are shown in the green track and differentially expressed genes are expressed in purple track. (B) An upregulated gene cluster related to glycine/betaine $\mathrm{ABC}$ transporter. (C) A downregulated gene cluster related to sugar $\mathrm{ABC}$ transporter.

A previous study has shown that the opuC operon (including OpuCA, OpuCB, OpuCC, and $\mathrm{OpuCD}$ ) plays an important role in osmoregulation in L. monocytogenes [33]. Therefore, under the treatment of MEL-A, the genes related to opuC operon are upregulated to maintain a stable osmotic pressure, which is consistent with the findings in Bacillus subtilis [34] and Staphylococcus aureus [35]. In addition, the glycine/betaine transport system was also found to contribute to bile (causing membrane damage) resistance in Enterococcus faecium [36]. Furthermore, the downregulated gene cluster (lmo2123-lmo2125) has been predicted to play an important role in encoding components of a maltodextrin $\mathrm{ABC}$ transporter system $[37,38]$. This might be an adaptive response of L. monocytogenes to MEL-A by shutting down certain transporters to reduce the bioactivity and permeability of cell membrane. Hence, the interference on bacterial transporter systems might be one of the antibacterial mechanisms of MEL-A.

\subsection{Real-Time PCR Analysis}

In order to confirm the RNA-Seq data, we analyzed the transcription levels of nine genes (Table S3) during growth in MEL-A treated BHI and untreated BHI by qPCR. As shown in Figure 8, the results of RNA-Seq and qPCR were highly consistent $\left(r^{2}=0.9986\right)$. 


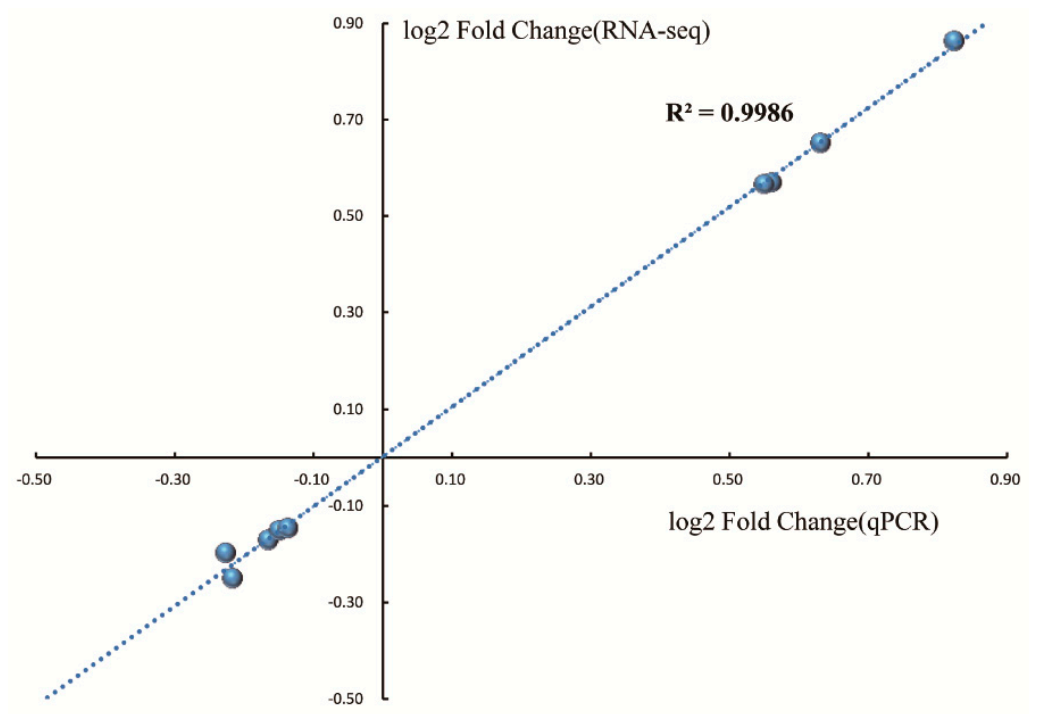

Figure 8. RT-qPCR validation of RNA-Seq experiments. The gene expression ratios obtained from both qPCR and RNA-Seq were normalized by a housekeeping control gene $\mathrm{drm}$. Each group was performed with three biological replicates.

\subsection{Antimicrobial Activity of MEL-A in Milk}

Milk was use as a model to examine the inhibitory effect of MEL-A on L. monocytogenes in real food systems. As we can see from Figure 9, when the concentration of MEL-A reached $1024 \mu \mathrm{g} / \mathrm{mL}$, there was an obvious inhibitory effect on the growth of L. monocytogenes in milk. The growth curve was almost $2 \log$ lower than that of the control group at $12 \mathrm{~h}$ and $24 \mathrm{~h}$. Nevertheless, no significant differences were found between the MEL-A-treated at $512 \mu \mathrm{g} / \mathrm{mL}$ and the control group. A likely explanation is that some complex food ingredients interfere with the function of MEL-A as previous findings [39]. Similarly, comparing Figure 9A with Figure 9B, there was no significant difference in the application of MEL-A in whole milk and skimmed milk. This finding indicates that MEL-A was not affected by the fat content in milk, showing its superiority over other antibacterial substances [17]. However, compared with the MIC values recorded in the culture media $(32 \mu \mathrm{g} / \mathrm{mL})$, the MIC value in milk $(1024 \mu \mathrm{g} / \mathrm{mL})$ was much higher. It may be attributed to the complexity of milk composition, since milk is rich in biomolecules and other components that may bind to MEL-A and interfere with its activity. Although the MIC in milk is relatively higher than that under experimental conditions, MEL-A could significantly inhibit the growth of L. monocytogenes in the real food system, implicating potential application prospects in the food industry by the further optimization or combination with other antibacterial substances.

A

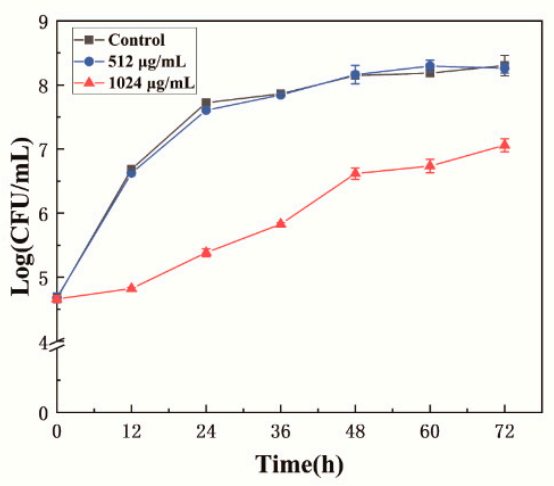

B

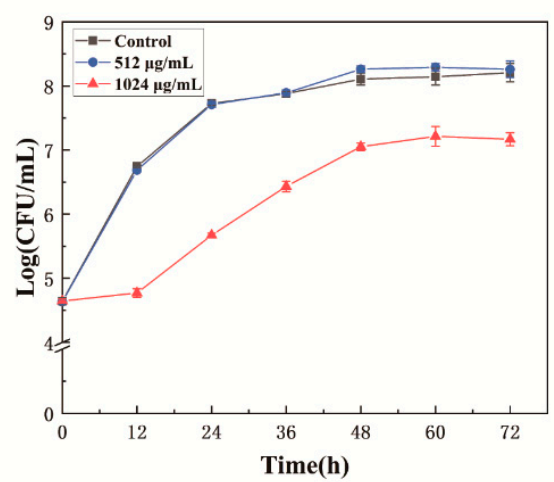

Figure 9. Effect of MEL-A on the growth of L. monocytogenes in whole milk (A) and skimmed milk (B) at room temperature $\left(25^{\circ} \mathrm{C}\right)$. Error bars are standard deviations $(n=3)$. 


\section{Conclusions}

In conclusion, this study identified and evaluated the bacteriostatic and bactericidal effect of MEL-A, on the important food-borne pathogen L. monocytogenes. This antibacterial activity is mainly attributed to the destruction of cell membrane and the impact on the ABC transport systems and stress response systems. In addition, L. monocytogenes could also be significantly inhibited by MEL-A when grown in milk. Although a relative high concentration is required in such a food model that may contain biomolecules and other components interfering with the activity of MEL-A, by further optimizing or combining with other antibacterial substances, this naturally produced and highly productive antibacterial agent could potentially be applied to the food industry for the control of food-borne pathogens.

Supplementary Materials: The following are available online. Figure S1: Inhibition effect of different concentrations of MEL-A on L. monocytogenes and other strains, Table S1: Fold change of major differentially expressed genes in Go enrichment analysis, Table S2: KEGG analysis, Table S3: qRT-PCR validation of RNA-seq experiments.

Author Contributions: Conceptualization, X.L., X.Z.; methodology, X.L., Q.S., X.P., Y.W. (Yansha Wu), W.Z. and Y.W. (Yajing Wu); formal analysis, X.L., X.Z., Q.C. and J.N.; investigation, X.L., Q.S., X.P., Y.W. (Yansha Wu), W.Z., Y.W. (Yajing Wu). and J.N.; data curation, X.L., Q.S., X.P.; writing-original draft preparation, X.L. and X.Z.; writing-review and editing, X.L., X.Z. and J.N.; funding acquisition, X.Z. All authors have read and agreed to the published version of the manuscript.

Funding: This work was supported by the National Key Research and Development Program of China (2018YFC1200100; 2019YFE0103900), the Natural Science Foundation of Shandong Province, China (ZR2019ZD21), and the Taishan Scholars Program of Shandong Province, China (ts20190955).

Conflicts of Interest: The authors declare no conflict of interest.

\section{References}

1. Donkor, E.S. Cockroaches and Food-borne Pathogens. Environ. Health Insights 2020, 14, 14. [CrossRef]

2. Scallan, E.; Hoekstra, R.M.; Widdowson, M.-A.; Hall, A.J.; Griffin, P.M. Food-borne illness acquired in the united states response. Emerg. Infect. Dis. 2011, 17, 1339-1340. [CrossRef]

3. Murray, E.G.D.; Webb, R.A.; Swann, M.B.R. A disease of rabbits characterised by a large mononuclear leucocytosis, caused by a hitherto undescribed bacillusBacterium monocytogenes (n.sp.). J. Pathol. Bacteriol. 1926, 29, 407-439. [CrossRef]

4. Schlech, W.F.; Lavigne, P.M.; Bortolussi, R.A.; Allen, A.C.; Haldane, E.V.; Wort, A.J.; Hightower, A.W.; Johnson, S.E.; King, S.H.; Nicholls, E.S.; et al. Epidemic Listeriosis-Evidence for Transmission by Food. N. Engl. J. Med. 1983, 308, 203-206. [CrossRef]

5. Churklam, W.; Chaturongakul, S.; Ngamwongsatit, B.; Aunpad, R. The mechanisms of action of carvacrol and its synergism with nisin against Listeria monocytogenes on sliced bologna sausage. Food Control 2020, 108, 106864. [CrossRef]

6. Thakur, M.; Asrani, R.K.; Patial, V. Chapter 6-Listeria monocytogenes: A Food-Borne Pathogen. In Food-Borne Diseases; Holban, A.M., Grumezescu, A.M., Eds.; Academic Press: Cambridge, MA, USA, 2018; pp. 157-192.

7. Radoshevich, L.; Cossart, P. Listeria monocytogenes: Towards a complete picture of its physiology and pathogenesis. Nat. Rev. Genet. 2017, 16, 32-46. [CrossRef]

8. Mukherjee, S.; Das, P.; Sen, R. Towards commercial production of microbial surfactants. Trends Biotechnol. 2006, 24, 509-515. [CrossRef]

9. Geetha, S.J.; Banat, I.M.; Joshi, S.J. Biosurfactants: Production and potential applications in microbial enhanced oil recovery (MEOR). Biocatal. Agric. Biotechnol. 2018, 14, 23-32. [CrossRef]

10. Arutchelvi, J.I.; Bhaduri, S.; Uppara, P.V.; Doble, M. Mannosylerythritol lipids: A review. J. Ind. Microbiol. Biotechnol. 2008, 35, 1559-1570. [CrossRef] [PubMed]

11. Kim, H.-S.; Yoon, B.-D.; Choung, D.-H.; Oh, H.-M.; Katsuragi, T.; Tani, Y. Characterization of a biosurfactant, mannosylerythritol lipid produced from Candida sp. SY16. Appl. Microbiol. Biotechnol. 1999, 52, 713-721. [CrossRef] 
12. Wu, J.; Shu, Q.; Niu, Y.; Jiao, Y.; Chen, Q. Preparation, Characterization, and Antibacterial Effects of Chitosan Nanoparticles Embedded with Essential Oils Synthesized in an Ionic Liquid Containing System. J. Agric. Food Chem. 2018, 66, 7006-7014. [CrossRef] [PubMed]

13. Shu, Q.; Niu, Y.; Zhao, W.; Chen, Q. Antibacterial activity and mannosylerythritol lipids against vegetative cells and spores of Bacillus cereus. Food Control 2019, 106, 106711. [CrossRef]

14. Fan, L.; Li, H.; Niu, Y.; Chen, Q. Characterization and Inducing Melanoma Cell Apoptosis Activity of Mannosylerythritol Lipids-A Produced from Pseudozyma aphidis. PLoS ONE 2016, 11, e0148198. [CrossRef] [PubMed]

15. Onghena, M.; Geens, T.; Goossens, E.; Wijnants, M.; Picó, Y.; Neels, H.; Covaci, A.; Lemière, F. Analytical characterization of mannosylerythritol lipid biosurfactants produced by biosynthesis based on feedstock sources from the agrofood industry. Anal. Bioanal. Chem. 2011, 400, 1263-1275. [CrossRef]

16. Andrews, J.M. Determination of minimum inhibitory concentrations. J. Antimicrob. Chemother. 2001, 48, 5-16. [CrossRef]

17. Pan, K.; Chen, H.; Davidson, P.M.; Zhong, Q. Thymol Nanoencapsulated by Sodium Caseinate: Physical and Antilisterial Properties. J. Agric. Food Chem. 2014, 62, 1649-1657. [CrossRef]

18. Ma, T.; Ouyang, T.; Ouyang, H.; Chen, F.; Peng, Z.; Chen, X.; Pang, D.; Ren, L. Porcine circovirus 2 proliferation can be enhanced by stably expressing porcine IL-2 gene in PK-15 cell. Virus Res. 2017, 227, 143-149. [CrossRef]

19. Motta, A.S.; Flores, F.S.; Souto, A.A.; Brandelli, A. Antibacterial activity of a bacteriocin-like substance produced by Bacillus sp. P34 that targets the bacterial cell envelope. Antonie Leeuwenhoek 2007, 93, 275-284. [CrossRef]

20. Wang, Z.; Zeng, Q.; Chen, T.; Liao, K.; Bu, Y.; Hong, S.; Hu, G. Silencing NFBD1/MDC1 enhances the radiosensitivity of human nasopharyngeal cancer $\mathrm{CNE} 1$ cells and results in tumor growth inhibition. Cell Death Dis. 2015, 6, e1849. [CrossRef]

21. Zhang, X.; De Maat, V.; Prieto, A.M.G.; Prajsnar, T.K.; Bayjanov, J.R.; De Been, M.; Rogers, M.R.C.; Bonten, M.J.; Mesnage, S.; Willems, R.J.L.; et al. RNA-seq and Tn-seq reveal fitness determinants of vancomycin-resistant Enterococcus faecium during growth in human serum. BMC Genom. 2017, 18, 893. [CrossRef]

22. Schmittgen, T.D.; Livak, K.J. Analyzing real-time PCR data by the comparative CT method. Nat. Protoc. 2008, 3, 1101-1108. [CrossRef]

23. Shu, Q.; Wei, T.; Lu, H.; Niu, Y.; Chen, Q. Mannosylerythritol lipids: Dual inhibitory modes against Staphylococcus aureus through membrane-mediated apoptosis and biofilm disruption. Appl. Microbiol. Biotechnol. 2020, 104, 5053-5064. [CrossRef]

24. Chen, J.; Wu, F.-X.; Luo, H.-L.; Liu, J.-J.; Luo, T.; Bai, T.; Li, L.-Q.; Fan, X.-H. Berberine upregulates miR-22-3p to suppress hepatocellular carcinoma cell proliferation by targeting Sp1. Am. J. Transl. Res. 2016, 8, 4932-4941. [PubMed]

25. Zhao, X.; Chen, L.; Wu, J.; He, Y.; Yang, H. Elucidating antimicrobial mechanism of nisin and grape seed extract against Listeria monocytogenes in broth and on shrimp through NMR-based metabolomics approach. Int. J. Food Microbiol. 2020, 319, 108494. [CrossRef]

26. Oussalah, M.; Caillet, S.; Lacroix, M. Mechanism of Action of Spanish Oregano, Chinese Cinnamon, and Savory Essential Oils against Cell Membranes and Walls of Escherichia coli O157:H7 and Listeria monocytogenes. J. Food Prot. 2006, 69, 1046-1055. [CrossRef] [PubMed]

27. Lin, L.; Gu, Y.L.; Li, C.Z.; Vittayapadung, S.; Cui, H.Y. Antibacterial mechanism of epsilon-Poly-lysine against Listeria monocytogenes and its application on cheese. Food Control 2018, 91, 76-84. [CrossRef]

28. Hyun, J.-E.; Lee, S.-Y. Antibacterial effect and mechanisms of action of 460-470 nm light-emitting diode against Listeria monocytogenes and Pseudomonas fluorescens on the surface of packaged sliced cheese. Food Microbiol. 2020, 86, 103314. [CrossRef]

29. Nescerecka, A.; Hammes, F.; Juhna, T. A pipeline for developing and testing staining protocols for flow cytometry, demonstrated with SYBR Green I and propidium iodide viability staining. J. Microbiol. Methods 2016, 131, 172-180. [CrossRef]

30. Huang, J.; Chen, B.; Li, H.; Zeng, Q.-H.; Wang, J.J.; Liu, H.; Pan, Y.; Zhao, Y. Enhanced antibacterial and antibiofilm functions of the curcumin-mediated photodynamic inactivation against Listeria monocytogenes. Food Control 2020, 108, 106886. [CrossRef]

31. Qian, J.; Zhang, M.; Dai, C.; Huo, S.; Ma, H. Transcriptomic analysis of Listeria monocytogenes under pulsed magnetic field treatment. Food Res. Int. 2020, 133, 109195. [CrossRef] 
32. Xie, Z.; Jian, H.; Jin, Z.; Xiao, X. Enhancing the Adaptability of the Deep-Sea Bacterium Shewanella piezotolerans WP3 to High Pressure and Low Temperature by Experimental Evolution under $\mathrm{H}_{2} \mathrm{O}_{2}$ Stress. Appl. Environ. Microbiol. 2017, 84. [CrossRef]

33. Fraser, K.R.; Harvie, D.; Coote, P.J.; O’Byrne, C.P. Identification and Characterization of an ATP Binding Cassette 1-Carnitine Transporter in Listeria monocytogenes. Appl. Environ. Microbiol. 2000, 66, 4696-4704. [CrossRef]

34. Kaan, T.; Homuth, G.; Mäder, U.; Bandow, J.E.; Schweder, T. Genome-wide transcriptional profiling of the Bacillus subtilis cold-shock response. Microbiology 2002, 148, 3441-3455. [CrossRef]

35. Schuster, C.F.; Bellows, L.E.; Tosi, T.; Campeotto, I.; Corrigan, R.M.; Freemont, P.; Gründling, A. The second messenger c-di-AMP inhibits the osmolyte uptake system OpuC in Staphylococcus aureus. Sci. Signal. 2016, 9, 81. [CrossRef]

36. Zhang, X.; Bierschenk, D.; Top, J.; Anastasiou, I.; Bonten, M.J.; Willems, R.J.L.; Van Schaik, W. Functional genomic analysis of bile salt resistance in Enterococcus faecium. BMC Genom. 2013, 14, 299. [CrossRef]

37. Mandin, P.; Repoila, F.; Vergassola, M.; Geissmann, T.; Cossart, P. Identification of new noncoding RNAs in Listeria monocytogenes and prediction of mRNA targets. Nucleic Acids Res. 2007, 35, 962-974. [CrossRef]

38. Gopal, S.; Berg, D.; Hagen, N.; Schriefer, E.-M.; Stoll, R.; Goebel, W.; Kreft, J. Maltose and maltodextrin utilization by listeria monocytogenes depend on an inducible abc transporter which is repressed by glucose. PLoS ONE 2010, 5, e10349. [CrossRef]

39. Chen, H.; Davidson, P.M.; Zhong, Q. Impacts of Sample Preparation Methods on Solubility and Antilisterial Characteristics of Essential Oil Components in Milk. Appl. Environ. Microbiol. 2013, 80, 907-916. [CrossRef]

Sample Availability: Samples of the compounds are not available from the authors.

Publisher's Note: MDPI stays neutral with regard to jurisdictional claims in published maps and institutional affiliations.

(C) 2020 by the authors. Licensee MDPI, Basel, Switzerland. This article is an open access article distributed under the terms and conditions of the Creative Commons Attribution (CC BY) license (http://creativecommons.org/licenses/by/4.0/). 